\title{
APLIKASI PENDUKUNG KEPUTUSAN PENENTUAN PROMOSI JABATAN MENGGUNAKAN METODE PROFILE MATCHING (STUDI KASUS DI PT. PETROKIMIA GRESIK)
}

\author{
(Application Of Position Promotion Decision Support Application Using Profile \\ Matching Method (Case Study At. Petrokimia Gresik)) \\ Wimpi Sancaka \\ Prodi. Teknik Informatika, Fakultas Teknik, Universitas Muhammadiyah Gresik \\ Jl. Sumatera No.101, Gn. Malang, Randuagung, Kec. Gresik, Kabupaten Gresik, Jawa Timur 61121 \\ Email : sancaka.wimpi@gmail.com
}

\begin{abstract}
Human resources play an essential role in helping companies to achieve their vision and mission. As a large scale company, PT Petrokimia Gresik obviously needs to invest in Employees' Performance Assessment System. It could act as a decision-making tool or a measure to evaluate and assess employees' performance at work so that theemployees' promotion would be moreobjective and organized. Decision support system could be used to reduce the subjectivity in decision-making process. The decision support system that uses profile matching method or competency gap analysis was created based on the data which refers to the decree of the board of directors issued by PT Petrokimia Gresik. This system analyzes and assesses employee's competencies by grouping and calculating core factors and secondary factors in each variable. The output of the calculation is a ranking of the candidates. By implementing decision support system which uses Profile Matching method, it assists company decision-making process in promotion decision based on employees' competency scores more optimally.
\end{abstract}

Key words : Decision Support System, Job Promotion, Profile Matching. Competency Gap, Core Factor, Secondary Factor.

\section{PENDAHULUAN}

Sumber daya manusia didalam suatu organisasi perusahaan merupakan hal yang sangat penting untuk mendukung kemajuan dan kualitas suatu perusahaan dalam mencapai tujuan yang lebih baik. Kenaikan jabatan merupakan faktor yang sangat penting bagi perencanaan karir seorang pegawai. Dalam hal ini proses evaluasi dan penilaian kinerja pegawai relatif sering dilakukan, sehingga perusahaan tersebut memerlukan suatu prosedur yang baku dalam menetapkan persyaratan bagi seorang karyawan untuk menempati jabatan tertentu dalam perusahaan. PT. Petrokimia Gresik adalah sebuah perusahaan yang bergerak dalam bidang industri kimia serta produsen pupuk terbesar di asia, dimana memiliki jumlah karyawan yang cukup banyak. Perusahaan ini dihadapkan pada kendala dalam bidang pengelolaan sumber daya manusia. Beberapa kendala tersebut yakni jumlah karyawan yang banyak, pengkaderan karyawan yang dinilai belum maksimal serta adanya subyektifitas dalam suatu promosi kenaikan jabatan.

Kenaikan jabatan merupakan salah satu faktor yang sangat penting bagi perencanaan karir pegawai dan juga untuk meremajakan suatu posisi jabatan agar diduduki oleh seorang yang mempunyai kriteria dan kemampuan yang cocok untuk menempati suatu jabatan yang diususlkan. Dalam pelaksanaanya beberapa masalah yang sering terjadi dalam proses evaluasi dan penilaian kinerja karyawan diantaranya adalah subyektifitas pengambilan keputusan. Subyektifitas yang dimaksud adalah jika karyawan langsung mendapatkan promosi jabatan dikarenakan pada satu kriteria penilaian saja tanpa melihat dari hasil penilaian yang lain, dimana subyektifitas ini terjadi untuk mengurangi kerumitan proses pengambilan keputusan akibat banyaknya alternatif pilihan. Selain itu proses kenaikan jabatan dan perencanaan karir pada perusahaan hanya didasarkan pada faktor tertentu saja, yakni tingkat penididikan, lamanya waktu bekerja serta golongan. Namun demikian masih terdapat banyak faktor lain untuk menilai seseorang dalam proses kenaikan jabatan yakni seperti daya tahan terhadap suatu masalah, ketekunan dan ketelitian atau keahlian lainnya yang dimiliki.

Proses pengambilan keputusan untuk promosi kenaikan jabatan dapat diselesaikan dengan sistem pendukung keputusan yang digunakan oleh manajer sebagai salah satu dukungan informasi dalam menyelesaikan permasalahan untuk mengisi jabatan, dimana fungsi kinerjanya dapat menghitung pertimbangan setiap kompetensi yang dimiliki masingmasing SDM. Diharapkan subyektifitas dalam pengambilan keputusan dapat dikurangi dan dapat diganti dengan kriteria penilaian yang lebih akurat yang digunakan sebagai promosi kenaikan jabatan, serta apabila hasil penilaian kurang memuaskan dapat dilakukan tindakan dan perencanaan jenjang karir guna memaksimalkan kinerja setiap karyawan. Untuk menyelesaikan permasalahan yang ada, maka penulis 
mengambil judul "Aplikasi Pendukung Keputusan Penentuan Promosi Jabatan menggunakan Metode Profile Matching (Studi Kasus di PT. Petrokimia Gresik) ".

\section{II.TINJAUAN PUSTAKA}

\section{A. Pengertian Sistem Pendukung Keputusan}

Sistem pendukung keputusan merupakan sebuah sistem yang digunakan untuk mendukung para pengambil keputusan dalam mengidentifikasi masalah, memilih data yang relevan, serta menentukan pendekatan yang digunakan dalam proses pengambilan keputusan sampai dengan tahap evaluasi pilihan alternatif yang ada. Konsep sistem pendukung keputusan diperkenalkan pertama kali oleh Michael S. Scoott Morton pada tahun 1970-an dengan istilah Management Decision System (Sprague, 1982). Sistem pendukung keputusan / Decision Support System (DSS) ini dimaksudkan menjadi alat bantu bagi para pengambil keputusan untuk memperluas kapabilitas mereka namun tidak untuk menggantikan penilaian mereka. Sistem itu digunakan untuk membantu pengambilan keputusan dalam situasi yang semiterstruktur dan situasi yang tidak terstruktur, dimana tak seorangpun tahu secara pasti bagaimana keputusan seharusnya dibuat (Alter, 2002).

\section{B. Pengertian Profile Matching}

Metode pencocokan profil atau profile matching adalah sebuah mekanisme pengambilan keputusan dengan mengasumsikan bahwa terdapat tingkat variabel prediktor yang ideal yang harus dipenuhi oleh subyek yang diteliti, bukan tingkat minimal yang harus dipenuhi atau dilewati. Dalam pencocokan profil, dilakukan identifikasi terhadap kelompok karyawan yang baik maupun buruk, karyawan yang mendekati profil ideal ialah seorang pegawai yang berhasil (Kusrini, 2007).

Metode profile matching sering juga disebut dengan metode gap, yaitu sebuah mekanisme pengambilan keputusan dengan mengasumsikan bahwa terdapat tingkat variabel prediktor yang ideal yang harus dimiliki oleh subyek yang dinilai (Mukhsin A, 2006). Dalam proses metode profile matching, secara garis besar merupakan proses membandingkan antara nilai data actual dari suatu profile yang akan dinilai dengan nilai profil yang diharapkan, sehingga dapat diketahui perbedaan kompetensinya atau disebut juga gap.

\section{Diagram Alir Sistem}

Diagram alir merupakan alur algoritma serta proses yang digunakan oleh sistem, berikut merupakan alur dari diagram alir sistem :

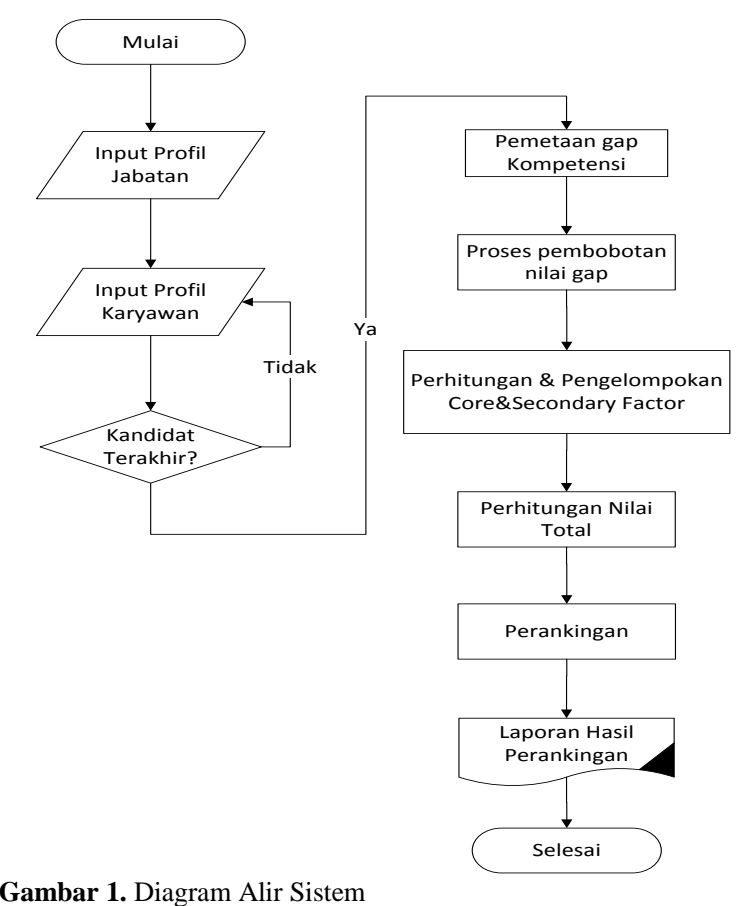

III.METODE PENELITIAN

\section{A. Analisis Sistem}

Tahap analisis dapat diketahui dengan jelas masalahmasalah yang terjadi, bagaimana user dapat menggunakan sistem yang berjalan sampai solusi yang dapat dijalankan untuk memecahkan permasalahan tersebut. Berdasarkan hasil penilaian yang dilakukan, didapatkan bahwa :

1) Kurang terstrukturnya data-data nilai kompetensi karyawan secara menyeluruh, sehingga akan membutuhkan waktu yang lama dalam setiap penilaian kenaikan jabatan.

2) Penganalisaan beberapa calon karyawan yang sesuai bobot nilai suatu jabatan masih dilakukan dengan membandingkan antar kandidat secara subyektif.

3) Proses penentuan syarat-syarat untuk kenaikan jabatan belum dilakukan secara otomatisasi dalam mengambil keputusan, sehingga terjadi ketidakefektifan dalam kinerja perusahaan.

\section{B. Perhitungan Profile Matching}

Perancangan proses perhitungan metode profile matching menurut Kusrini (2007), langkah pertama adalah menentukan Bobot Nilai Gap. Pada tahap ini akan ditentukan bobot nilai masing- masing aspek dengan menggunakan bobot nilai yang telah ditentukan bagi masing-masing aspek itu sendiri. Adapun inputan dari proses pembobotan ini adalah selisih dari profil karyawan dan profil jabatan.

Langkah pertama yakni dengan melakukan pemetaan Gap. Gap yang dimaksud adalah perbedaan antara profil jabatan dengan profil karyawan.

Gap $=$ Profil Karyawan - Profil Jabatan 
Langkah kedua dengan Melakukan pencocokan dengan table bobot Gap Hasil Gap dari pengurangan profil karyawan dan profil jabatan bila dicocokkan dengan kolom selisih gap pada table bobot nilai yang dihasilkan.

Langkah ketiga yakni dengan melakukan perhitungan Nilai Total. Setelah menentukan bobot nilai gap untuk variabel yang dibutuhkan, kemudian tiap sub variabel dikelompokkan lagi menjadi core factor dan secondary factor. Core factor merupakan aspek (kompetensi) yang paling dibutuhkan oleh suatu jabatan, untuk menghitung nya digunakan rumus :

$$
\begin{aligned}
& \mathrm{NCF}=\frac{\sum N C\left(x_{. .}\right)}{\sum I C} \\
& \mathrm{NRC}=\text { Nilai rata-rata core factor } \\
& \mathrm{NC}=\text { Jumlah total nilai core factor } \\
& \mathrm{IC}=\text { Jumlah item tiap variabel }
\end{aligned}
$$

Secondary factor adalah item-item selain aspek yang ada pada core factor. Berikut rumus yang digunakan :

$$
\begin{aligned}
& \mathrm{NSF}=\frac{\sum N S(x . .)}{\sum I S} \\
& \mathrm{NSF}=\text { Nilai rata-rata secondary factor } \\
& \mathrm{NS} \quad=\text { Jumlah total nilai secondary factor } \\
& \mathrm{IS} \quad=\text { Jumlah item tiap variabel }
\end{aligned}
$$

Langkah keempat yakni menentukan Nilai Total dengan memasukkan rumus perhitungan dari tiap variabel yang ada.

$\mathrm{NT}=(\mathrm{x}) \% \cdot \mathrm{NCF}(\mathrm{x})+(\mathrm{x}) \% \cdot \mathrm{NSF}(\mathrm{x})$

$\mathrm{NT}=$ Nilai total dari variabel

$\mathrm{NCF}(\mathrm{x})=$ Nilai rata-rata core factor variabel

$\mathrm{NSF}(\mathrm{x})=$ Nilai rata-rata secondary factor variabel

$(\mathrm{x}) \%=$ Nilai persen yang diinputkan (total 100\%)

Langkah kelima yakni menentukan Hasil Akhir perhitungan dengan menentukan ranking, berikut rumusnya :

$\mathrm{HA}=(\mathrm{x}) \% \cdot \mathrm{NT}(1)+(\mathrm{x}) \% \cdot \mathrm{NT}(2)+(\mathrm{x}) \% \cdot \mathrm{NT}(3)+$ (4)

HA : Hasil akhir

NT(1) : Nilai total variabel 1

NT(2) : Nilai total variabel 2

NT(3) : Nilai total variabel 3

(x)\% : Nilai prosentase setiap variabel (total 100\%)

\section{HASIL DAN PEMBAHASAN}

\section{A. Desain Implementasi}

Penerapan hasil dari desain dan analisis dapat dilihat pada gambar berikut, halaman menu beranda depan sistem.

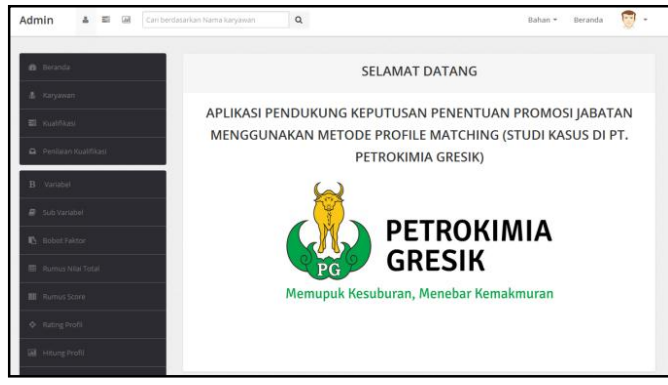

Gambar 2. Halaman Menu Beranda

Halaman penilaian kualifikasi karyawan merupakan syarat awal kualifikasi berkas ataupun ketentuan yang harus dipenuhi terlebih dahulu oleh karyawan.

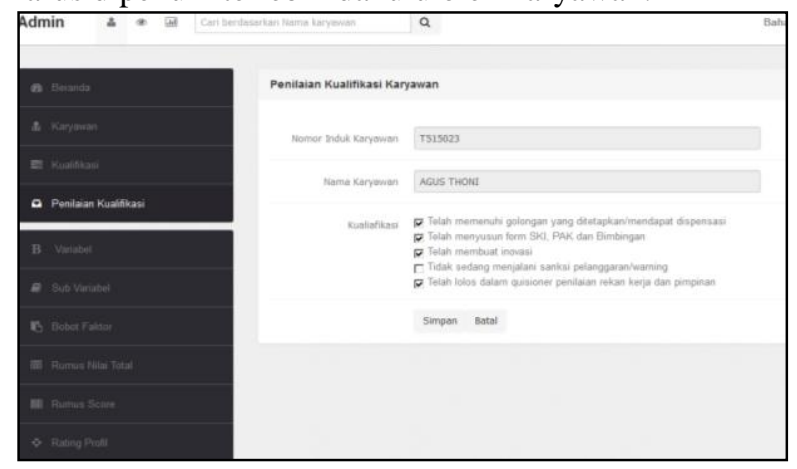

Gambar 3. Halaman Penilaian Kualifikasi Karyawan

Proses rating profil jabatan dapat dilakukan setelah pada proses sebelumnya yakni kualifikasi karyawan terpenuhi yakni mendapatkan minimal 3 point dari syarat kualifikasi,

berikut adalah proses penilaian rating profil karyawan pada aplikasi pendukung keputusan.

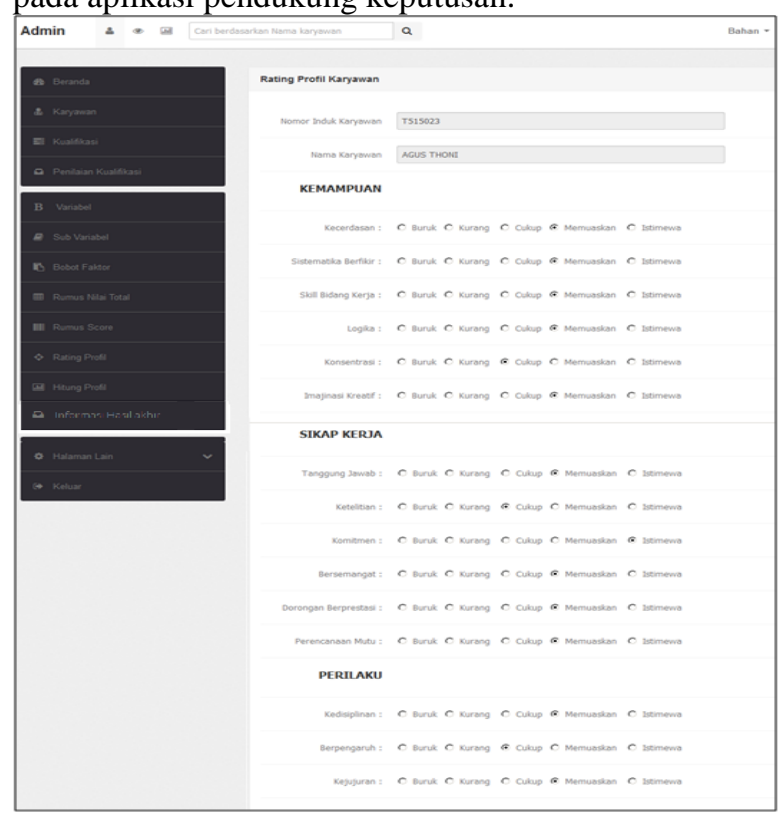

Gambar 4. Halaman Rating Profil Karyawan

Proses hitung profil merupakan output terakhir atas perhitungan dari sistem dimana akan dihasilkan nilai 
akhir serta ranking karyawan. Berikut dapat dilihat dari hasil proses hitung profil.

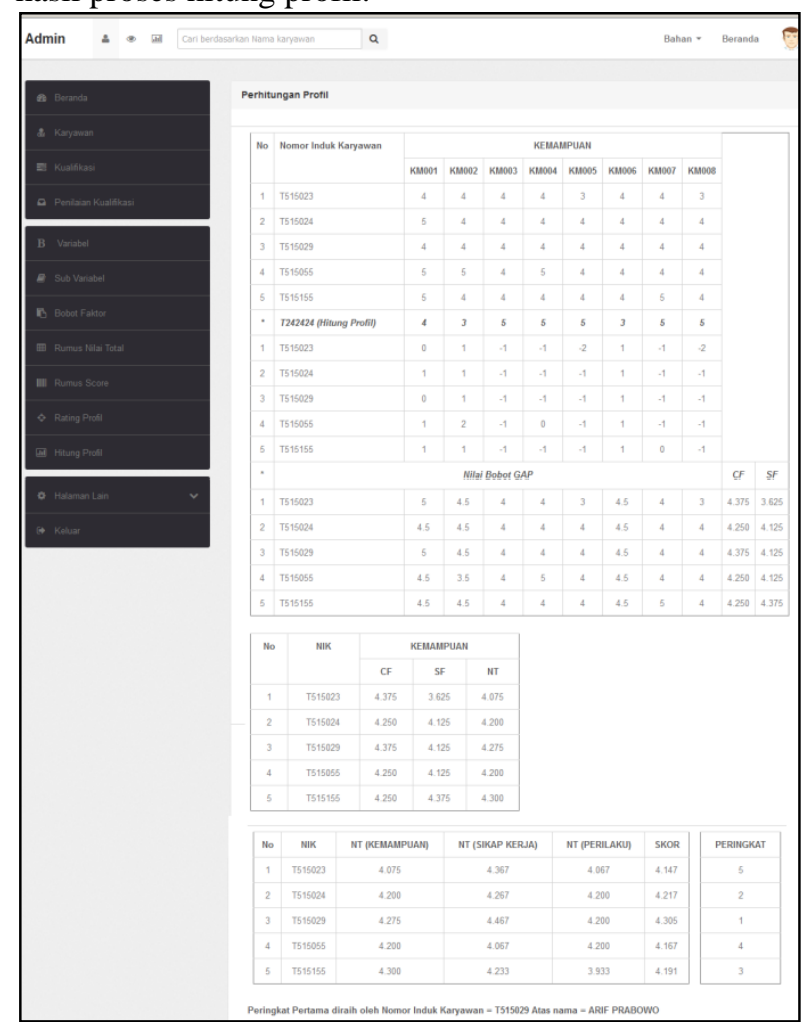

Gambar 5. Halaman Hitung Profil Karyawan

\subsection{Pengujian Sistem}

Pengujian sistem yang telah dibangun dilakukan dengan menerapkan pengujian perhitungan manual dengan membandingkan perhitungan excel dan sistem.

TABLE I. Perhitungan Nilai AKHIR EXCEL

\begin{tabular}{|c|c|c|c|c|c|c|}
\hline No & NIK & NT(kp) & NT(sk) & NT(pk) & SKOR & Ranking \\
\hline 1 & T515023 & 4,075 & 4,36667 & 4,06666 & 4,1458 & 5 \\
\hline 2 & $T 515024$ & 4,2 & 4,26667 & 4,2 & 4,2166 & 2 \\
\hline 3 & $T 515029$ & 4,275 & 4,46667 & 4,2 & 4,3041 & 1 \\
\hline 4 & T515055 & 4,2 & 4,06667 & 4,2 & 4,1666 & 4 \\
\hline 5 & $T 515155$ & 4,3 & 4,23333 & 3,93333 & 4,1916 & 3 \\
\hline
\end{tabular}

Berikut adalah hasil perhitungan nilai akhir / perankingan pada sistem :

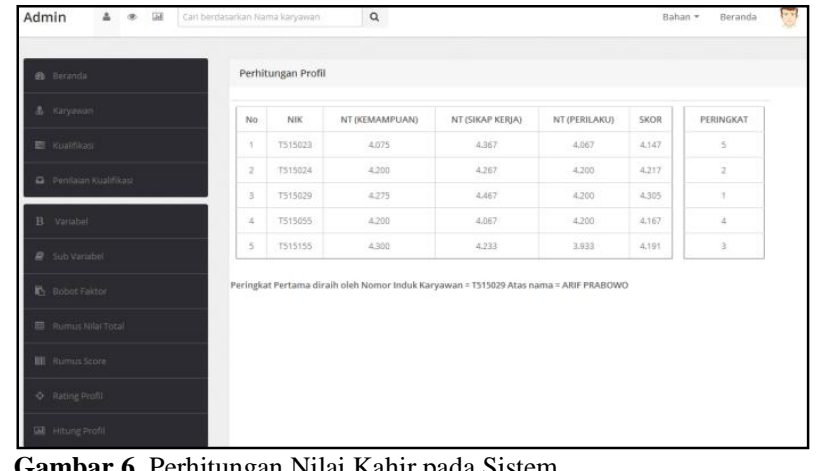

Gambar 6. Perhitungan Nilai Kahir pada Sistem

\section{PENUTUP}

\subsection{Kesimpulan}

Berdasarkan hasil pengujian yang dilakukan pada penelitian ini, maka disimpulkan bahwa :

1. Secara fungsional bahwa sistem yang telah dibangun dapat diterim dan dapat menghasilkan output penilaian yang diharapkan oeh Kepala Bagian dengan menghilangkan subyektifitas penilaian.

Sistem yang telah dibangun dapat membantu mempersingkat waktu penilaian Kepala Bagian untuk merekomendasikan karyawan yang akan diajukan untuk mendapat promosi jabatan.

\section{PENUTUP}

\section{A. Kesimpulan}

Berdasarkan hasil pengujian yang dilakukan pada penelitian ini, maka disimpulkan bahwa :

1) Secara fungsional bahwa sistem yang telah dibangun dapat diterim dan dapat menghasilkan output penilaian yang diharapkan oeh Kepala Bagian dengan menghilangkan subyektifitas penilaian.

2) Sistem yang telah dibangun dapat membantu mempersingkat waktu penilaian Kepala Bagian untuk merekomendasikan karyawan yang akan diajukan untuk mendapat promosi jabatan.

\section{B. Saran}

Beberapa saran untuk pengembangan sistem lebih lanjut, yaitu:

1) Sistem hanya mampu melakukan 1 kali penilaian untuk setiap perhitungan proses promosi jabatan, maka sebaiknya perlu ditambahkan fitur penyimpanan untuk tiap proses perhitungan yang dilakukan.

Perlunya akses halaman tambahan untuk user karyawan yang mengikuti seleksi, agar dapat mengetahui seluruh proses penilaian. 


\section{DAFTAR PUSTAKA}

[1] Budyanto, Dhony Harry., dan Soleman, Arief. Optimalisasi Sitem Pendukung Keputusan Penilaian Kinerja Pegawai untuk Penentuan Pegawai Berprestasi dengan Metode Profile Matching.Jurnal Teknologi Informasi, Volume 9 No.2, Oktober 2013.

[2] Effendi, Onong Uchjana. (1989). Sistem Informasi Manjemen. Bandung : Mandar Maju.

[3] Hamalik, Oemar. (1993). Pengelolaan Sistem Informasi. Bandung : Trigenda Karya.

[4] Hariandja, Marihot Tua Efendi (2007). Manajemen Sumber Daya Manusia : Pengadaan,Pengembangan,Pengkompensasian,dan Peningkatan Produktivitas Pegawai. Jakarta : Grasindo.

[5] Hidayat, Arif Lukman., dan Pinandita, Tito. (2013). Sistem Pendukung Keputusan Evaluasi Kinerja Kryawan untuk Promosi Jabatan Struktural pada Bimbingan Belajar Sciencemaster menggunakan Metode Gap Kompetensi (Profil Matching). Purwokerto : Jurnal Teknologi Technoscientia Vol.5 No.2 Februari 2013.

[6] Jogiyanto. (2005). Analisis dan Desain Sistem Informasi. Yogyakarta : Andi.

[7] Kusrini. (2007). Konsep dan Aplikasi Sistem Pendukung Keputusan. Yogyakarta : Andi.

[8] McLeod, Raymond. (2001). Sistem Informasi Manajemen, Jilid 1, Edisi Ketujuh. Jakarta : Prenhallindo.

[9] Muqtadir, Asfan., dan Purdianto, Irwan. (2013). Sistem Pendukung Keputusan Kenaikan Jabatan Menggunakan Metode Profil Matching (Studi Kasus PT. Industri Kemasan Semen Gresik). Yogyakarta : SNATI.

[10] Sarumaha, Kardiaman Lius. (2014). SistemPendukung Keputusan Pemelihan Jabatan Area Supervisor pada PT. Indomarco Prismatama dengan Metode Profile Mathing. Pelita Informatika Budi Darma, Volume : VI, No.1, Maret 2014.

[11] Sutanta, Edhy. (2003). Sistem Informasi Manajemen. Yogyakarta : Graha Ilmu. 